Article

\title{
No Association between Metabolic Syndrome and Periodontitis in Korean Postmenopausal Women
}

\author{
Jeong-In Kim ${ }^{1}$, Choong-Ho Choi ${ }^{1,2}$ and Ki-Ho Chung ${ }^{1,2, *}$ \\ 1 Department of Preventive \& Public Health Dentistry, Chonnam National University, Gwangju 61186, Korea; \\ kji6298@naver.com (J.-I.K.); hochoi@chonnam.ac.kr (C.-H.C.) \\ 2 Dental Science Research Institute, School of Dentistry, Chonnam National University, Gwangju 61186, Korea \\ * Correspondence: prevention@chonnam.ac.kr; Tel.: +82-62-530-5858
}

\section{check for}

updates

Citation: Kim, J.-I.; Choi, C.-H.; Chung, K.-H. No Association between Metabolic Syndrome and Periodontitis in Korean

Postmenopausal Women. Int. J. Environ. Res. Public Health 2021, 18, 11110. https://doi.org/10.3390/ ijerph182111110

Academic Editors: Maria Alexandra Bernardo, Vanessa Machado and João Botelho

Received: 11 September 2021 Accepted: 21 October 2021 Published: 22 October 2021

Publisher's Note: MDPI stays neutra with regard to jurisdictional claims in published maps and institutional affiliations.

Copyright: (c) 2021 by the authors. Licensee MDPI, Basel, Switzerland. This article is an open access article distributed under the terms and conditions of the Creative Commons Attribution (CC BY) license (https:// creativecommons.org/licenses/by/ $4.0 /)$.
Abstract: This study aimed to determine the association between metabolic syndrome (MetS) and periodontitis in Korean postmenopausal women. The study selected 3320 menopause women (40-79-year-old) from those who participated in the seventh Korea National Health and Nutrition Survey (2016-2018). This association was determined using frequency and multiple logistic regression analyses. The prevalence of MetS in postmenopausal women was 33.2\%, and among the MetS components, abdominal obesity showed a higher odds ratio of periodontitis by 1.36 ( $95 \%$ confidence interval (CI): $1.12-1.65 ; p<0.05)$. The odds ratio for periodontitis was 1.34 times higher $(95 \%$ CI: 1.12-1.60) in the MetS prevalence group with three or more MetS components $(p<0.05)$; however, after adjusting for demographic characteristics and health behavior variables, it was not statistically significant. Therefore, our results indicated that MetS has no association with periodontitis in postmenopausal women after adjusting for confounding variables.

Keywords: postmenopausal; metabolic syndrome; periodontitis; oral health behavior

\section{Introduction}

According to Organization for Economic Cooperation and Development (OECD) Health Statistics 2019, the life expectancy of Korean women is 85.7 years, which is 2.3 years longer than the OECD average of 83.4 years [1]. As the average lifespan of women has increased, the span of middle and old age have been extended, interest in the health of postmenopausal women has increased, and importance of health management is evolving. The average age of the onset of menopause for women is 49.4 years [2], which can be a major turning point in terms of life and health for middle- and old-aged women.

Menopause is a state in which the ovarian function decreases and causes a decline in estrogen levels secreted by the ovaries and cessation of menstruation [3]. In women, menopause is known to increase the risk of metabolic syndrome (MetS) by $60 \%$ independent of age, body mass index, and physical activity beyond the simple cessation of menstruation [4]. Changes in the distribution of fat in the body, such as postmenopausal abdominal obesity, neutrophil counts, and total cholesterol levels increase the incidence of cardiovascular disease [5-7].

Owing to changes in diet and lifestyle, more than one disease exists simultaneously in modern society, including diabetes, hypertension, obesity, and hyperlipidemia [8]. MetS is a condition in which hypertension, diabetes, hyperlipidemia, and cardiovascular disease risk factors such as insulin resistance, advanced age, increased body mass index, and smoking are seen [6]. It has recently become clear that non-alcoholic fatty liver disease is a systemic disease and may play a key role in MetS [9]. MetS has also been reported to be associated with periodontal disease and tooth loss [10].

Periodontal disease is one of the most common chronic inflammatory diseases, and severe periodontitis causes periodontal tissue destruction, leading to tooth loss [11]. Peri- 
odontal disease is also known to induce or sustain a systemic chronic inflammatory state, facilitating arteriosclerosis and increasing the incidence of cardiovascular disease [12].

Various studies have reported the connection between metabolic diseases (such as obesity, cardiovascular disease, and diabetes) and periodontitis [13-16], and the connection between MetS and periodontitis is being elucidated [17-21]. Some studies have demonstrated the effect of adult MetS components on periodontitis, and this relationship has also been reported in Korea [16,21-24]; however, regional and global studies are insufficient for the relationship between menopause MetS and periodontitis.

Therefore, the hypothesis of this study was established that the MetS component of postmenopausal women was related to periodontal disease.

\section{Materials and Methods}

\subsection{Study Population}

The study was conducted in accordance with the Declaration of Helsinki and the protocol was approved by the Ethics Committee of the Institutional Review Board of Korea Centers for Disease Control and Prevention (2018-01-03-P-A).

The total number of participants who enrolled in the seventh Korea National Health and Nutrition Examination Survey (KNHANES; 2016-2018) was 24,269, and 3320 postmenopausal women (40-79-year-old) were included in this study, from the 16,489 individuals who participated in the oral examination.

\subsection{Assessment of MetS}

MetS was assessed on the following five components: (1) abdominal obesity (waist circumference of $\geq 85 \mathrm{~cm}$ for females); (2) high blood pressure (systolic $\geq 130 \mathrm{mmHg}$ and diastolic $\geq 85 \mathrm{mmHg}$ ); (3) fasting serum glucose level $\geq 100 \mathrm{mg} / \mathrm{dL}$; (4) hypertriglyceridemia (serum triglyceride $>150 \mathrm{mg} / \mathrm{dL}$ ); (5) low high-density lipoprotein (HDL) cholesterol levels ( $<50 \mathrm{mg} / \mathrm{dL}$ for females).

MetS was diagnosed if three or more of the five components were identified using the National Cholesterol Education Program Adult Treatment Panel standard III [25] and abdominal obesity was assessed using the Korean Society for the Study of Obesity standard [26].

\subsection{Assessment of Periodontitis}

Periodontitis was assessed based on the Community Periodontal Index of Treatment Needs certified by the World Health Organization, in 1982, and uses the Community periodontal index (CPI) [27], which generally reflects periodontal conditions. The CPI score is classified as " $0-2$ " no periodontitis and " $3-4$ " periodontitis.

\subsection{Assessment of Confounders}

Among the variables surveyed in the seventh KNHANES (2016-2018), age, education, household income, smoking, drinking, stress, oral examination, daily toothbrushing frequency, use of oral hygiene products, and chewing and speaking challenges were used as variables. Ages were classified into "40-49 years," "50-59 years," "60-69 years," and "70-79 years." Educational level was classified as " $\leq$ elementary school," "middle school," "high school," and " $\geq$ college;" household income level was classified as "Lowest," "Second lowest," "Second highest," and "Highest" based on quartiles (households). Drinking was classified as "No" for not drinking at all in the past year, "Low" for less than once a month to less than four times a month, and "High" for more than 2-4 times a week. Smoking and occasional smoking were classified as "Current." Consequently, those who smoked in the past but not currently smoked were classified as "Past" and those who never smoked were classified as "No." Stress was classified as "Very severe," "Severe", "Occasionally," and "Rarely." Oral examinations were classified as "Yes" and "No" if they had or had not undergone oral examinations in the past 1 year, respectively. The daily brushing frequency was classified as " $\leq 1$, " " 2, " and " $\geq 3$," and the use of oral hygiene products was classified as "Yes" and "No." Chewing and speech problems were classified as "uncomfortable" for very 
uncomfortable and uncomfortable and "comfortable" for mediocre, not uncomfortable, or not at all uncomfortable.

\subsection{Statistical Analyses}

A complex sample design was applied for the data analysis, and the statistical significance level of 0.05 was used for all analyses. Frequency analysis was performed to identify the participants' socio-demographic characteristics, health status and behavior, MetS, and periodontitis. Multiple logistic regression analysis was performed to verify the difference in periodontitis according to MetS. The Statistical Package for the Social Sciences (SPSS), version 26.0 (IBM SPSS Statistics for Windows, Armonk, NY, USA) was used for all statistical analyses.

\section{Results}

\subsection{MetS Characteristics}

As a result of the analysis, abdominal obesity, hypertension, hyperglycemia, hypertriglyceridemia, and low-HDL cholesterol levels were seen in $35.9 \%, 38.6 \%, 43.1 \%$, $27.7 \%$, and $44.7 \%$ of the participants. The prevalence of MetS with three or more of these components was $33.2 \%$ (Table 1 ).

Table 1. Distribution of MetS and its components.

\begin{tabular}{cccc}
\hline Variables & Classification & $\boldsymbol{n}$ & $\%$ \\
\hline \multirow{2}{*}{ Abdominal obesity } & $<85 \mathrm{~cm}$ & 2092 & 64.1 \\
& $\geq 85 \mathrm{~cm}$ & 1219 & 35.9 \\
\hline \multirow{2}{*}{ Hypertension } & $<130 / 85 \mathrm{mmHg}$ & 1985 & 31.4 \\
& $\geq 130 / 85 \mathrm{mmHg}$ & 1333 & 38.6 \\
\hline \multirow{2}{*}{ Hyperglycemia } & $<100 \mathrm{mg} / \mathrm{dL}$ & 1803 & 56.9 \\
& $\geq 100 \mathrm{mg} / \mathrm{dL}$ & 138 & 43.1 \\
\hline \multirow{2}{*}{ Hypertriglyceridemia } & $<150 \mathrm{mg} / \mathrm{dL}$ & 2295 & 72.3 \\
& $\geq 150 \mathrm{mg} / \mathrm{dL}$ & 897 & 27.7 \\
\hline \multirow{2}{*}{ Low HDL cholesterol } & $\geq 50 \mathrm{mg} / \mathrm{dL}$ & 1728 & 55.3 \\
& $<50 \mathrm{mg} / \mathrm{dL}$ & 1461 & 44.7 \\
\hline \multirow{2}{*}{ MetS $^{1}$} & Less than 3 & 2086 & 66.8 \\
\hline
\end{tabular}

Frequency analysis; ${ }^{1}$ MetS is defined when three or more of abdominal obesity, hypertension, hyperglycemia, hypertriglyceridemia, low HDL-Cholesterol.

\subsection{Periodontitis Prevalence according to Socio-Demographic Characteristics and Health Status and Behavior}

As a result of analyzing the distribution of periodontal disease according to the sociodemographic characteristics and health status and behavior, the prevalence of periodontitis was the highest among those in their $70 \mathrm{~s}$ at $39.9 \%$ and the lowest at $25.7 \%$ in their $40 \mathrm{~s}$. The prevalence of periodontal disease as per the education status was the highest at $42.6 \%$ in elementary school and below and the lowest at $28.8 \%$ in college and above. The prevalence of periodontitis as per the income level was the highest at $41.1 \%$ in the lowest group and the lowest at $31.4 \%$ in the highest group $(p<0.05$, Table 2$)$.

As a result of analyzing the distribution of periodontitis according to health status and behavior, the prevalence of periodontitis was the highest in current smokers at $57.7 \%$. Moreover, $40.2 \%$ of individuals did not undergo oral examination in the last year, which was higher than those who underwent oral examination. The frequency of daily brushing was more than once in $41.1 \%$ of individuals, and proxabrush, dental floss, and mouthwash were not used by $38.0 \%, 39.4 \%$, and $39.4 \%$ of individuals, respectively. Chewing caused discomfort in $44.3 \%$ of individuals, whereas there was comfortable in $33.7 \%$ of individuals $(p<0.05$, Table 2$)$. 
Table 2. Periodontitis according to socio-demographics characteristics and health status and behavior.

\begin{tabular}{|c|c|c|c|c|}
\hline \multirow{2}{*}{ Variables } & \multirow{2}{*}{$n$} & \multicolumn{2}{|c|}{ Periodontitis Status } & \multirow{2}{*}{$p$-Value ${ }^{1}$} \\
\hline & & Yes & No & \\
\hline \multicolumn{5}{|l|}{ Age } \\
\hline $40-49$ & $97(100)$ & $21(25.7)$ & $76(74.3)$ & \multirow{4}{*}{0.020} \\
\hline $50-59$ & $1106(100)$ & $376(34.1)$ & $730(65.9)$ & \\
\hline $60-69$ & $1170(100)$ & $464(38.6)$ & $706(61.4)$ & \\
\hline $70-79$ & $947(100)$ & $381(39.9)$ & $566(60.1)$ & \\
\hline \multicolumn{5}{|l|}{ Education } \\
\hline$\leq$ Elementary school & $1474(100)$ & $635(42.6)$ & $839(57.4)$ & \multirow{4}{*}{0.000} \\
\hline Middle school & $571(100)$ & $199(35.9)$ & $372(64.1)$ & \\
\hline High school & $830(100)$ & $279(33.0)$ & $551(67.0)$ & \\
\hline$\geq$ College & $444(100)$ & $129(28.8)$ & $315(71.2)$ & \\
\hline \multicolumn{5}{|l|}{ Household income } \\
\hline Lowest & $1017(100)$ & $420(41.1)$ & $597(58.9)$ & \multirow{4}{*}{0.004} \\
\hline Second lowest & $912(100)$ & $359(38.4)$ & $553(61.6)$ & \\
\hline Second highest & $719(100)$ & $250(35.0)$ & $469(65.0)$ & \\
\hline Highest & $663(100)$ & $209(31.4)$ & $454(68.6)$ & \\
\hline \multicolumn{5}{|l|}{ Drinking } \\
\hline No & $754(100)$ & $269(35.0)$ & $485(65.0)$ & \multirow{3}{*}{0.089} \\
\hline Low & $1478(100)$ & $542(35.8)$ & $936(64.2)$ & \\
\hline High & $229(100)$ & $104(44.0)$ & $125(56.0)$ & \\
\hline \multicolumn{5}{|l|}{ Smoking } \\
\hline No & $3095(100)$ & $1137(36.2)$ & $1958(63.8)$ & \multirow{3}{*}{0.000} \\
\hline Past & $104(100)$ & $36(32.7)$ & $68(67.3)$ & \\
\hline Current & $121(100)$ & $69(57.7)$ & $52(42.3)$ & \\
\hline \multicolumn{5}{|l|}{ Stress } \\
\hline Very severe & $176(100)$ & $69(36.1)$ & $107(639)$ & \multirow{4}{*}{0.342} \\
\hline Severe & $647(100)$ & $264(39.2)$ & $383(60.8)$ & \\
\hline Occasionally & $1771(100)$ & $628(35.5)$ & $1143(64.5)$ & \\
\hline Rarely & $715(100)$ & $279(39.3)$ & $436(60.7)$ & \\
\hline \multicolumn{5}{|l|}{ Oral exam within 1 year } \\
\hline No & $2237(100)$ & $901(40.2)$ & $1336(59.8)$ & \multirow[b]{2}{*}{0.000} \\
\hline Yes & $1083(100)$ & $341(30.3)$ & $742(69.7)$ & \\
\hline \multicolumn{5}{|c|}{ Daily toothbrushing frequency } \\
\hline$\leq 1$ & $315(100)$ & $122(41.1)$ & $193(58.9)$ & \multirow{3}{*}{0.008} \\
\hline$\overline{2}$ & $1412(100)$ & $571(39.6)$ & $841(60.4)$ & \\
\hline$\geq 3$ & $1593(100)$ & $549(33.9)$ & $1044(66.1)$ & \\
\hline \multicolumn{5}{|l|}{ The use of proxabrush } \\
\hline Non-use & $2848(100)$ & $1087(38.0)$ & $1761(62.0)$ & \\
\hline Use & $472(100)$ & $155(30.6)$ & $317(69.4)$ & 0.005 \\
\hline The use of dental floss & & & & \\
\hline Non-use & $2749(100)$ & $1096(39.4)$ & $1653(60.6)$ & \\
\hline Use & $571(100)$ & $146(25.6)$ & $425(74.4)$ & 0.000 \\
\hline The use of mouthwash & & & & \\
\hline Non-use & $2379(100)$ & $944(39.4)$ & 1435 (60.6) & $0 \cap 0 \cap$ \\
\hline Use & $941(100)$ & $298(31.3)$ & $643(68.7)$ & 0.000 \\
\hline Chewing difficulty & & & & \\
\hline Discomfort & $1100(100)$ & $483(44.3)$ & $617(55.7)$ & \\
\hline No discomfort & $2207(100)$ & $755(33.7)$ & $1452(66.3)$ & 0.000 \\
\hline Speaking difficulty & & & & \\
\hline Uncomfortable & $424(100)$ & $173(41.4)$ & $251(58.6)$ & \\
\hline Comfortable & $2883(100)$ & $1065(36.4)$ & $1818(63.6)$ & 0.104 \\
\hline
\end{tabular}




\subsection{Association between MetS and Its Components and Periodontitis}

Logistic regression analysis was performed to verify the association between the MetS components and periodontitis. As a result of the analysis, the odds ratio was 1.36 times higher in the abdominal obesity group $(p<0.05)$, and it was not statistically significant in hypertension, hyperglycemia, hypertriglyceridemia, and low-HDL cholesterol groups (Table 3).

Table 3. The association between MetS and periodontitis.

\begin{tabular}{ccc}
\hline Variables & Model 1 & Model 2 \\
\cline { 2 - 3 } & Crude OR (95\% CI ${ }^{+}$) & AOR $^{\mathbf{1}} \mathbf{( 9 5 \%} \mathbf{~ C I}^{+}$) \\
\hline Abdominal obesity (ref. = No) & $1.36(1.12-1.65)$ & \\
Hypertension (ref. = No) & $1.04(0.87-1.23)$ & \\
Hyperglycemia (ref. = No) & $1.11(0.94-1.31)$ & \\
Hypertriglyceridemia (ref. = No) & $1.08(0.89-1.32)$ & \\
Low HDL cholesterol (ref. = No) & $1.06(0.89-1.27)$ & $1.14(0.92-1.42)$ \\
MetS (ref. = No) & $1.34(1.12-1.60)$ &
\end{tabular}

${ }^{1}$ Adjusted odds ratio; ${ }^{\dagger} 95 \%$ confidence interval. Odds ratios and $95 \%$ confidence intervals are estimated using complex samples multivariable logistic regression analysis. Model 2 is an adjusted odds ratio considering age, education, household income, drinking, smoking, an oral examination within the past 1 year, daily toothbrushing frequency, the use of proxabrush, the use of dental floss, the use of mouthwash, and chewing and speaking difficulty.

Multiple logistic regression analysis was performed to verify the association between MetS and periodontitis. As a result of the analysis, the odds ratio was 1.34 times higher in the MetS group $(p<0.05)$; however, it was not statistically significant after adjusting for socio-demographic characteristics and health status and behavior $(p>0.05$, Table 3$)$.

\section{Discussion}

In women, the prevalence of cardiovascular disease increases because of changes in female hormones related to menopause from the age of 40 , which escalates the body fat accumulation, and physical changes with aging [28], and it is known that the cardiovascular disease mortality rate is high in menopausal women with MetS [29]. Additionally, as periodontal disease is closely related to systemic disease, it occurs or worsens because of weakened immunity and systemic diseases, such as respiratory and cardiovascular diseases, the prevalence of which increases with age [30]. It has been suggested that the common cause between periodontitis and MetS is inflammation [31]. Periodontal-produced inflammatory cytokines or periodontal pathogens/LPS enter the systemic circulation and thus affect other parts of the body, promoting or inducing the development of MetS [32]. It has been reported that a $10 \%$ increase in the number of sites with BOP is associated with increased diagnosis of MetS [33].

As a result of this study, the prevalence of MetS among postmenopausal women was determined as $33.2 \%$, which was higher than the prevalence of MetS among the Korean adult women in 2008 (20.5\%) and 2017 (18.7\%) [34]. Lim et al. [35] showed a high prevalence of MetS in men under the age of 50 years and women above the age of 50 years, and menopause is known to increase MetS risk independent of age or body mass index and physical activity [4].

The periodontitis prevalence showed a high rate in the case of not receiving regular check-ups in the past year and less frequent brushing in health status and behavior [36,37], similar to the findings reported by Lee [38], who reported that the number of remaining teeth was high in the group that brushed more than three times daily. The prevalence of periodontal disease was higher in the group not using proxabrush, dental floss, or mouthwash, consistent with the study conducted by Han et al. [23], in which the risk of periodontal disease was 2.69 times higher in the non-flossing group of postmenopausal women, and the study of Park [39], where the prevalence of periodontal disease was high when proxabrush and dental floss were not used. 
Among the MetS components, the prevalence of periodontitis was 1.36 and 1.34 times higher in the abdominal obesity and MetS prevalence groups, respectively; however, it was not significant after adjustment. This was significantly related only to the abdominal obesity group among MetS risk factors and was consistent with the results of the study conducted by LaMonte et al. [40], which showed that the prevalence of periodontitis was 1.74 times higher in the presence of supragingival plaque. According to the study results of Habashneh et al. [41], postmenopausal women with a BMI of 25 or higher had a lower risk of periodontitis compared to normal weight but showed a significantly higher loss of clinical attachment loss, plaque index, and calculus index, which partially coincided. Additionally, it was significant in diabetes and abdominal obesity, and it was consistent with the study results of Han [42], which showed a significant association with $\mathrm{CPI}$ as the number of risk factors for MetS increased. According to Kang et al. [43], the prevalence of periodontitis was significantly higher in fasting glucose, HDL cholesterol, and abdominal obesity, and the odds ratio for hypertension was significantly higher in the model corrected for health behavior and oral health behavior. According to a Kim [37], the risk of periodontitis in the hypertensive group was 1.60 times higher whereas the risk of periodontal disease was 2.22 times higher when 1 or more MetS risk factors were present. Additionally, it was partially consistent with the study result of Baek et al. [44], which showed that the risk of having periodontitis together was also high when three or more were present. Morita et al. [19] also found a 2.40 times higher risk of periodontitis in patients with MetS, Campos et al. [45] showed a 2.02 times higher prevalence of periodontitis in MetS patients, and a study by Gomes-Filho et al. [46] showed approximately 2 times higher probability of having moderate or severe periodontitis in individuals without periodontitis.

Similar to the findings [47], which suggest that cardiovascular disease risk factors are among the important causes of MetS in this study, it was established that menopause is an independent risk factor for periodontitis as abdominal obesity increases because of changes in body fat distribution. Thus, it is recommended that measures to prevent abdominal obesity in postmenopausal women should be explored.

This was a cross-sectional study that utilized the data from KNHANES to determine the association between MetS and periodontitis in Korean postmenopausal women, with a limitation of being unable to present an accurate causal association. MetS may only be a predictor, not a causal factor with periodontal disease. In addition, the use of hormone therapy in postmenopausal women and the drug use status of patients with metabolic diseases could not be investigated, which may have acted as a confounding variable in this study. However, using KNHANES data which possibly represent the national population, it was demonstrated that MetS is not associated with periodontitis in postmenopausal women. Thus, more in-depth studies are needed to determine the factors affecting the association between MetS and periodontitis in postmenopausal women.

\section{Conclusions}

We demonstrated that MetS has no association with periodontitis in postmenopausal women after adjusting for confounding variables.

Author Contributions: All authors contributed extensively to the work presented in this paper. J.-I.K. wrote the entire manuscript. C.-H.C. provided the idea for the study. K.-H.C. conceived the study as well as coordinated in and helped with the drafting of the manuscript. All authors have read and agreed to the published version of the manuscript.

Funding: This research was funded by a grant (BCRI121010) of Chonnam National University Hospital Biomedical Research Institute.

Institutional Review Board Statement: The institutional review board (IRB) at the Korea Cen-ter for Disease Control and Prevention approved the seventh KNHANES, 2016-2018 (2018-01-03-P-A). All procedures were conducted according to the ethical principles of the Decla-ration of Helsinki.

Informed Consent Statement: Informed consent was obtained from all subjects involved in the study. 
Data Availability Statement: The dataset analyzed for this study can be found at https:// knhanes. kdca.go.kr/knhanes/eng/index.do (accessed on 17 October 2021).

Conflicts of Interest: The authors declare no conflict of interest.

\section{References}

1. Ministry of Health \& Welfare. OECD Health Statistics 2019; Ministry of Health \& Welfare: Seoul, Korea, 2019.

2. National Health Insurance Service. Health Insurance Statistics; National Health Insurance Service: Seoul, Korea, 2011.

3. Lee, M.S.; Km, J.H.; Park, M.S.; Yang, J.; Ko, Y.H.; Ko, S.D.; Joe, S.H. Factors influencing the severity of menopause symptoms in Korean post-menopausal women. J. Korean Med. Sci. 2010, 25, 758-765. [CrossRef]

4. Polotsky, H.N.; Polotsky, A.J. Metabolic implications of menopause. Semin. Reprod. Med. 2010, 28, 426-434. [CrossRef]

5. Kim, I.K.; Choi, H.M.; Kim, M.H. Menopausal Knowledge and Management in Peri-menopausal Women. J. Korean Soc. Menopause 2012, 18, 124-131. [CrossRef]

6. Park, H.S.; O, S.U.; Kang, J.H.; Park, Y.U.; Choe, J.M.; Kim, Y.S. Prevalence and associated factors with metabolic syndrome in South Korea from the Korean national health and nutrition examination survey 1998. J. Korean Oph. Opt. Soc. 2013, 12, 1-14.

7. Carr, M.C. The emergence of the metabolic syndrome with menopause. J. Clin. Endocrinol. Metab. 2003, 88, 2404-2411. [CrossRef]

8. Ministry of Health \& Welfare. In-Depth Analysis on the 3rd (2005) Korea Health and Nutrition Examination Survey: Nutrition Survey; Ministry of Health \& Welfare: Seoul, Korea, 2007.

9. Milovanovic, T.; Pantic, I.; Dragasevic, S.; Lugonja, S.; Dumic, I.; Rajilic-Stojanovic, M. The Interrelationship Among Non-Alcoholic Fatty Liver Disease, Colonic Diverticulosis and Metabolic Syndrome. J. Gastrointest. Liver Dis. 2021, 30, $274-282$.

10. Kang, H.J. A study on periodontal disease and tooth loss in metabolic syndrome patient. J. Dent. Hyg. Sci. 2015, 15, 445-456. [CrossRef]

11. Pihlstrom, B.L.; Michalowicz, B.S.; Johnson, N.W. Periodontal diseases. Lancet 2005, 366, 1809-2010. [CrossRef]

12. Moon, Y.S. Factors on Korean people over 30s' Dental caries and Periodontal diseases. Master's Thesis, University of Dankook, Seoul, Korea, 2015.

13. Seo, D.G. Association between oral health status and diabetes in Korean adults. Ph.D. Thesis, University of Yonse, Seoul, Korea, 2012.

14. Lee, K.D.; Lee, H.K. DMFT Index, Periodontal Index and Oral Hygiene Status in Diabetic Patients. Yeungnam Univ. J. Med. 2005, 22, 62-71. [CrossRef]

15. Saito, T.; Shimazaki, Y.; Kiyohara, Y.; Kato, I.; Kubo, M.; Iida, M.; Yamashita, Y. Relationship between obesity, glucose tolerance, and periodontal disease in Japanese women: The Hisayama study. J. Periodontal Res. 2005, 40, 346-353. [CrossRef] [PubMed]

16. Kim, H.D.; Park, D.M.; Ko, D.H.; Paik, D.L. Influence of cardiovascular related disease on periodontitis. J. Korean Acad. Oral Health 2006, 30, 46-55.

17. Shimazaki, Y.; Saito, T.; Yonemoto, K.; Kiyohara, Y.; Iida, M.; Yamashita, Y. Relationship of metabolic syndrome to periodontal disease in Japanese women: The Hisayama study. J. Dent. Res. 2007, 86, 271-275. [CrossRef] [PubMed]

18. Kushiyama, M.; Shimazaki, Y.; Yamashita, Y. Relationship between metabolic syndrome and periodontal disease in Japanese adults. J. Periodontol. 2009, 80, 1610-1615. [CrossRef] [PubMed]

19. Morita, T.; Ogawa, Y.; Takada, K.; Nishinoue, N.; Sasaki, Y.; Motohashi, M.; Maeno, M. Association between periodontal desease and metabolic syndrome. J. Public Health Dent. 2009, 69, 248-253. [CrossRef]

20. Morita, T.; Yamazaki, Y.; Mita, A.; Takada, K.; Seto, M.; Nishinoue, N.; Sasaki, Y.; Motohashi, M.; Maeno, M. A cohort study on the association between periodontal disease and the development of metabolic syndrome. J. Periodontol. 2010, 81, 512-519. [CrossRef]

21. Kim, J.S.; Kim, S.Y.; Byon, M.J.; Lee, J.H.; Jeong, S.H.; Kim, J.B. Association between components of metabolic syndrome and periodontitis in Korean adults aged 35-79 years. J. Korean Acad. Oral Health 2019, 43, 142-148. [CrossRef]

22. Lee, S.J.; Hong, Y.M.; Back, J.H.; Nam, Y.S. The relationship between metabolic syndrome and periodontal disease except patients with hypertension and type 2 diabetes mellitus in Korea. J. Korean Acad. Oral Health 2009, 33, 451-460.

23. Han, D.H.; Lim, S.Y.; Sun, B.C.; Paek, D.; Kim, H.D. The association of metabolic syndrome with periodontal disease is confounded by age and smoking in a Korean population: The Shiwha-Banwol Environmental Health Study. J. Clin. Periodontol. 2010, 37, 609-616. [CrossRef]

24. Jung, J.O. Effects of Metabolic Syndrome on Periodontal diseases in Korean Adults. J. Dent. Hyg. 2012, 12, $245-252$.

25. Grundy, S.M.; Cleeman, J.I.; Daniels, S.R.; Donato, K.A.; Eckel, R.H.; Franklin, B.A.; Gordon, D.J.; Krauss, R.M.; Savage, P.J.; Smith Jr, S.C.; et al. American Heart Association; National Heart, Lung, and Blood Institute. Diagnosis and management of the metabolic syndrome: An American Heart Association/National Heart, Lung, and Blood Institute scientific statement. Circulation 2005, 112, 2735-2752. [CrossRef]

26. Yoon, Y.S.; Oh, S.W. Optimal waist circumference cutoff values for the diagnosis of abdominal obesity in Korean adults. J. Clin. Endocrinol. Metab. 2014, 29, 418-426. [CrossRef] [PubMed]

27. Barmes, D. CPITN-A WHO initiative. Int. Dent. J. 1994, 44, 523-525.

28. Yeoum, S.G. The Investigation on The Risk Factors of Cardiovascular Disease for Postmenopausal Women Over 50 Years. J. Menopausal Med. 2003, 9, 266-272.

29. Shin, H.M. The Influence on Cardiovascular Mortality of the Metabolic Syndrome in Korean Postmenopausal Women. J. Menopausal Med. 2012, 18, 6-14. [CrossRef] 
30. Park, J.Y. The Impacts of Metabolic Syndrome Among the Korea Adults on Periodontal Disease: The 6th Korean National Health and Nutrition Examination Survey (2013). Ph.D. Thesis, University of Yeungnam, Gyeongsan, Korea, 2016.

31. Genco, R.J.; Grossi, S.G.; Ho, A.; Nishimura, F.; Murayama, Y. A proposed model linking inflammation to obesity, diabetes, and periodontal infection. J. Periodontol. 2005, 76, 2075-2084. [CrossRef]

32. Watanabea, K.; Chob, Y.D. Periodontal disease and metabolic syndrome: A qualitative critical review of their association. Arch. Oral Biol. 2014, 59, 855-870. [CrossRef]

33. D'Aiuto, F.; Sabbah, W.; Netuveli, G.; Donos, N.; Hingorani, A.D.; Deanfield, J.; Tsakos, G. Association of the metabolic syndrome with severe periodontitis in a large US population-based survey. J. Clin. Endocrinol. Metab. 2008, 93, 3989-3994. [CrossRef] [PubMed]

34. Kim, M.H.; Lee, S.H.; Shin, K.S.; Son, D.Y.; Kim, S.H.; Joe, H.; Yoo, B.W.; Hong, S.H.; Cho, C.Y.; Shin, H.S.; et al. The Change of Metabolic Syndrome Prevalence and Its Risk Factors in Korean Adults for Decade: Korea National Health and Nutrition Examination Survey for 2008-2017. Korean J. Fam. Pract. 2020, 1, 44-52. [CrossRef]

35. Lim, S.; Shin, H.; Song, J.H.; Kwak, S.H.; Kang, S.M.; Yoon, J.W.; Choi, S.H.; Cho, S.I.; Park, K.S.; Lee, H.K.; et al. Increasing prevalence of metabolic syndrome in Korea: The Korean National Health and Nutrition Examination Survey for 1998-2007. Diabetes Care. 2011, 34, 1323-1328. [CrossRef]

36. Kim, Y.H. Relevance of the metabolic syndrome and periodontal disease according to menopausal status. Ph.D. Thesis, University of Dong-Eui, Busan, Korea, 2016.

37. Kim, S.Y.; Jang, H.G. Influence of metabolic on periodontal disease in Korean adults. J. Korean Soc. Dent. Hyg. 2015, 15, 39-410. [CrossRef]

38. Lee, K.S.; Kim, C.S. Association between bone mineral density and remaining teeth in postmenopausal women. J. Korean Soc. Dent. Hyg. 2014, 14, 319-326. [CrossRef]

39. Park, S.J. The association of metabolic syndrome and periodontitis. based on data of Korean national health and nutrition survey. Master's Thesis, University of Chungang, Seoul, Korea, 2011.

40. LaMonte, M.J.; Williams, A.M.; Genco, R.J.; Andrews, C.A.; Hovey, K.M.; Millen, A.E.; Browne, R.W.; Trevisan, M.; WactawskWende, J. Association between metabolic syndrome and periodontal disease measures in postmenopausal women: The Buffalo OsteoPerio study. J. Periodontol. 2014, 85, 1489-1501. [CrossRef]

41. Habashneh, R.A.; Azar, W.; Shaweesh, A.; Khader, Y. The relationship between body mass index and periodontitis among postmenopausal women. Obes. Res. Clin. Pract. 2016, 10, 15-23. [CrossRef]

42. Han, S.J. Associations among the health status, behavior, and periodontitis in Korean adults with metabolic syndrome. J. Korean Soc. Dent. Hyg. 2020, 20, 313-324.

43. Kang, H.J.; Yul, B.C. Relationship between metabolic syndrome and oral diseases in the middle aged and elderly people. J. Korean Soc. Dent. Hyg. 2015, 15, 947-961. [CrossRef]

44. Baek, H.J.; Choi, Y.H.; Lee, S.G.; Song, K.B.; Kwon, H.J. The association of metabolic syndrome and periodontitis in Korean adult population. J. Korean Acad. Oral Health 2010, 34, 338-345.

45. Campos, J.R.; Costa, F.O.; Cota, L.O.M. Association between periodontitis and metabolic syndrome: A case-control study. J. Periodontol. 2020, 91, 784-791. [CrossRef]

46. Gomes-Filho, I.S.; Balinha, I.; Cruz, S.S.; Trindade, S.C.; Cerqueira, E.M.M.; Passos-Soares, J.S.; Coelho, J.M.F.; Ladeia, A.M.T.; Vianna, M.I.P.; Hintz, A.M.; et al. Moderate and severe periodontitis are positively associated with metabolic syndrome. Clin. Oral Investig. 2021, 25, 3719-3727. [CrossRef]

47. Lee, S.Y.; Park, H.S.; Kim, D.J.; Han, J.H.; Kim, S.M.; Cho, G.J.; Kim, D.Y.; Kwon, H.S.; Kim, S.R.; Lee, C.B.; et al. Appropriate waist circumference cutoff points for central obesity in Korean adults. Diabetes Res. Clin. Pract. 2007, 75, 72-80. [CrossRef] 